University of Nebraska - Lincoln

DigitalCommons@University of Nebraska - Lincoln

$11-1-1999$

\title{
The predictive use of event-related potentials in language development and the treatment of language disorders
}

\author{
Dennis L. Molfese \\ University of Nebraska-Lincoln, dmolfese2@unl.edu \\ Victoria J. Molfese \\ University of Nebraska - Lincoln, vmolfese2@unl.edu \\ K. A. Espy \\ University of Nebraska-Lincoln, kespy2@unl.edu
}

Follow this and additional works at: https://digitalcommons.unl.edu/dcnlfacpub

Part of the Neurosciences Commons

Molfese, Dennis L.; Molfese, Victoria J.; and Espy, K. A., "The predictive use of event-related potentials in language development and the treatment of language disorders" (1999). Developmental Cognitive Neuroscience Laboratory - Faculty and Staff Publications. 25.

https://digitalcommons.unl.edu/dcnlfacpub/25

This Article is brought to you for free and open access by the Developmental Cognitive Neuroscience Laboratory at DigitalCommons@University of Nebraska - Lincoln. It has been accepted for inclusion in Developmental Cognitive Neuroscience Laboratory - Faculty and Staff Publications by an authorized administrator of DigitalCommons@University of Nebraska - Lincoln. 


\title{
The Predictive Use of Event-Related Potentials in Language Development and the Treatment of Language Disorders
}

\author{
Dennis L. Molfese, Victoria J. Molfese, \\ and Kimberly A. Espy \\ Department of Psychology and Behavioral \& Social Sciences \\ School of Medicine, Southern Illinois University, Carbondale, IL
}

This article attempts to relate what is currently known regarding the brain's involvement in language processing during the early years of life. This article focuses on the event-related potential (ERP) as a means to study the neuroelectrical correlates of language in the brains of infants and children. After reviewing general information concerning ERPs and language, this presentation relates how neonatal ERP measures of phonetic discrimination predict later language and reading abilities.

\section{THE USE OF ERP TECHNIQUES TO STUDY BRAIN-BEHAVIOR RELATIONS}

The event-related potential (ERP) is a synchronized portion of the ongoing electroencephalogram pattern that is time-locked to the onset of some event in the infant's environment (Rockstroh, Elbert, Birbaumer, \& Lutzenberger, 1982). The ERP is characterized by a complex waveform that varies in amplitude and frequency over time and is thought to reflect ongoing brain processing. Fluctuations in the amplitude or latency of various positive or negative peaks within the ERP occur at different points throughout its time course (Callaway, Tueting, \& Koslow, 1978). Research over the past 70 years has demonstrated that the ERP, because of this time-locked feature, can be used to effectively study both general and specific aspects of the organism's response to its external and internal environments in addition to an individual's perceptions and decisions (Molfese, 1983; Nelson \& Salapatek, 1986; Ruchkin, Sutton, Munson, Silver, \& Macar, 1981). Given that the ERP technique does not require a planned and overt response from individuals from which it is recorded, it is particularly well-suited for the neuropsychological study

\section{Copyright (@ 2000 All Rights Reserved}


of the infant's and the child's early language development (Molfese, Freeman, \& Palermo, 1975). One major advantage of the ERP is that it provides very fine temporal information (down to $1 \mathrm{msec}$ or less) regarding the brain's response to language input. In addition, it does have some gross-level spatial resolution capabilities that permit speculation concerning the distribution of brain mechanisms that subserve functions such as language.

\section{PHONETIC DISCRIMINATIONS AND ERPS}

Building on a base of behavioral research (Liberman, Cooper, Shankweiler, \& Studdert-Kennedy, 1967), studies by Molfese and colleagues of voice onset time (VOT) and place of articulation (POA) have covered the developmental period extending from infancy into childhood and adulthood (for a review see Molfese \& Betz, 1988). In general, these results suggest that the infant's ability to discriminate speech sounds is present at birth for some speech cues whereas the infant's ability to discriminate other speech cues arises later in development. Thus, some of the infant's perception of speech cues such as VOT follow different developmental progressions and emerge after 2 to 3 months of age whereas their perception of other cues such as POA is present at birth.

POA has been investigated in a number of studies with infants and adults (Molfese \& Betz, 1988). As in the case of the VOT temporal cue, these studies of the POA cue identified both lateralized and bilateral hemisphere responses that discriminated between different consonant sounds.

\section{MULTIVARIATE APPROACHES TO LANGUAGE PREDICTION USING ERPS TO PREDICT LATER DEVELOPMENT}

Given that infants discriminate speech sounds at birth, are there any implications of such abilities for later language development? In fact, one recent development trend in the study of ERP correlates of language acquisition is the use of ERPs to predict later language development (Molfese \& Molfese, 1985, 1997). Such studies have recorded ERPs to speech sounds in very young infants and then used these brain responses to predict factors such as later vocabulary size. These results have been used to argue that neonatal auditory discrimination abilities as measured by ERPs are an important factor for later language development. Newborn infants who could discriminate between consonant sounds alone and consonant sounds in combination with different vowel sounds performed better on language tasks at age 3 years. Such a pattern of responding suggests that more linguistically advanced children are already at an advantage at birth because their nervous systems can make finer discriminations along a variety of different dimensions. As Molfese (1989) suggested, "Perhaps the earlier an infant can discriminate between speech sounds

\section{Copyright $(2000$ All Rights Reserved}


in its environment, the more likely that the infant will be able to use such information to discriminate word sound differences" (p. 55). Such early discrimination abilities may later play a major role in the infant and young child's vocabulary, syntax, and perhaps even reading development.

Molfese and Molfese (1985) noted that analyses of the ERPs elicited by speech sounds indicated that electrophysiological measures recorded at birth could identify children who performed better or worse on language tasks 3 years later. Two particularly important components in the brain waves were identified. One component of the auditory ERP that occurred between 88 and $240 \mathrm{msec}$ reliably discriminated between children whose McCarthy Verbal Index scores (McCarthy, 1972) were above 50 (the High group) and those with lower scores (the Low group). Only ERPs recorded over the left hemisphere of the High group systematically discriminated between the different consonant speech sounds. The right hemisphere responses of this group, on the other hand, discriminated between the different nonspeech stimuli. The Low group displayed no such lateralized discrimination for either the speech or the nonspeech sounds. A second component of the ERP with a late peak latency of $664 \mathrm{msec}$ also discriminated between the High and Low groups. Unlike the earlier component, however, the second component occurred over both hemispheres and, consequently, reflected bilateral activity. This second component differed in other ways from the first component. Whereas the second component discriminated between speech and nonspeech sounds, this discrimination depended on which vowel followed the consonant. Subsequent replications have reported similar findings (Molfese, 1989, 1992; Molfese \& Searock, 1986) with different populations of children. Furthermore, Molfese and Molfese (1997) reported that the ability to predict later language skills from newborn ERPs continued through 5 years of age.

This relation holds through 8 years of age for both predicting verbal skills as well as reading skills. When the neonatally obtained ERPs recorded from these children were used to predict verbal skills using the verbal subscale of the Wechsler Intelligence Scale for Children (3rd ed.; $M=107.2, S D=11.7$, range $=78-137$ ) to measure vocabulary, verbal comprehension, similarities, digit span, and information in these children, two discriminant functions classified these children with $77 \%$ accuracy (Wilks's $\lambda=.499), \chi^{2}(16)=67.08, p<.00001$, and (Wilks's $\lambda=$ $.748), \chi^{2}(7)=28.003, p<.0002$. Twelve of 14 children $(86 \%)$ were correctly classified as members of the Low group, 55 of 76 children (72\%) were correctly classified as Average, with 11 (15\%) misclassified to the Low group and $10(13 \%)$ to the High group, and 12 of 13 children were correctly classified as belonging to the High group (92\%).

Furthermore, developmentally, the pattern of change in the ERP waveform also was found to be related to verbal intellectual skills at age 8 . Hierarchical growth curve models of change in the waveform latency of three peaks $\left(\mathrm{N}_{2}, \mathrm{P}_{3}\right.$, and $\left.\mathrm{N}_{4}\right)$ from ages 1 through 8 years predicted verbal intellectual (the Verbal Comprehension IQ

\section{Copyright $(2000$ All Rights Reserved}


Factor Score) skills measured at age 8. Verbal intellectual skills were parsed into Low $(\leq 95)$ and High groups (>95). For the left hemisphere, the expected latency of $\mathrm{N}_{2}$ in the Low children was $25 \mathrm{msec}$ longer than that of the High children at age 8 . The linear rate of decline in $\mathrm{N}_{2}$ latency across age was significantly slower in the Low group. In High children, the peak latency for $\mathrm{N}_{2}$ declined an average of $12.6 \mathrm{msec}$ per year, whereas the rate of change was $-7.7 \mathrm{msec}$ per year in the Low group. Parallel results were found for $\mathrm{P}_{3}$ latencies in the left hemisphere. There were no significant group differences in the developmental trajectory of $\mathrm{N}_{4}$ latency. In the right hemisphere, none of the peak latencies predicted verbal intellectual skills at age 8 . These findings represent a simple, but exciting, beginning in investigating the manner by which changes in brain function are related to neuropsychological skill development. They also raise the possibility that interventions, initiated early in development based on such early identification of potential language problems, may lead to the elimination of verbal problems later in life.

\section{ACKNOWLEDGMENTS}

Support for this work was provided by the National Institutes of Health (R01-HD17860).

\section{REFERENCES}

Callaway, C., Tueting, P., \& Koslow, S. (1978). Event-related brain potentials and behavior. New York: Academic.

Liberman, A. M., Cooper, F. S., Shankweiler, D., \& Studdert-Kennedy, M. (1967). Perception of the speech code. Psychological Review, 74, 431-461.

McCarthy, D. (1972). Manual for the McCarthy scales of children's abilities. New York: Psychological Corporation.

Molfese, D. L. (1983). Event related potentials and language processes. In A. W. K. Gaillard \& W. Ritter (Eds.), Tutorials in ERP research-Endogenous components (pp. 345-368). Amsterdam: Elsevier.

Molfese, D. L. (1989). The use of auditory evoked responses recorded from newborns to predict later language skills. In N. W. Paul (Ed.), Research in infant assessment (Vol. 25, No. 6, pp. 47-62). White Plains, NY: March of Dimes.

Molfese, D. L. (1992). The use of neuropsychological measures to predict long-term outcomes in newborn human infants. In M. G. Tramontana \& S. R. Hooper (Eds.), Advances in child neuropsychology (Vol. 1, pp. 1-23). New York: Springer-Verlag.

Molfese, D. L., \& Betz, J. C. (1988). Electrophysiological indices of the early development of lateralization for language and cognition and their implications for predicting later development. In D. L. Molfese \& S. J. Segalowitz (Eds.), The developmental implications of brain lateralization for language and cognitive development (pp. 171-190). New York: Guilford.

Molfese, D. L., Freeman, R., \& Palermo, D. (1975). The ontogeny of lateralization for speech and nonspeech stimuli. Brain and Language, 2, 356-368.

Molfese, D. L., \& Molfese, V. J. (1985). Electrophysiological indices of auditory discrimination in newborn infants: The basis for predicting later language development. Infant Behavior and Development, 8, 197-211.

\section{Copyright $(2000$ All Rights Reserved}


Molfese, D. L., \& Molfese, V. J. (1997). Discrimination of language skills at five years of age using event-related potentials recorded at birth. Developmental Neuropsychology, 13, 135-156.

Molfese, D. L., \& Searock, K. (1986). The use of auditory evoked responses at one year of age to predict language skills at 3 years. Australian Journal of Communication Disorders, 14, 35-46.

Nelson, C. A., \& Salapatek, P. (1986). Electrophysiological correlates of infant recognition memory. Child Development, 57, 1483-1497.

Rockstroh, B., Elbert, T., Birbaumer, N., \& Lutzenberger, W. (1982). Slow brain potentials and behavior. Baltimore: Urban-Schwarzenberg.

Ruchkin, D., Sutton, S., Munson, R., Silver, K., \& Macar, F. (1981). P300 and feedback provided by absence of the stimulus. Psychophysiology, 18, 271-282.

\section{Copyright (@ 2000 All Rights Reserved}

